\title{
Afeto e desigualdade: gênero, geração e classe entre empregadas domésticas e seus empregadores*
}

\author{
Jurema Brites
}

\section{Resumo}

Na realização das tarefas de cuidado e manutenção das famílias de camadas médias no Brasil - desempenhada, na esmagadora maioria das vezes, por mulheres pobres, fora da parentela dos empregadores - assim como nas formas de remuneração e de relacionamento que se desenvolvem entre patrões e empregadas domésticas, reproduz-se um sistema altamente estratificado de gênero, classe e cor. A manutenção desse sistema hierárquico que o serviço doméstico desvela tem sido reforçada, em particular, por uma ambigüidade afetiva entre os empregadores - sobretudo as mulheres $e$ as crianças $-e$ as trabalhadoras domésticas. Ao analisar exemplos tirados de uma pesquisa etnográfica em Vitória (Espírito Santo), comentaremos como essa ambigüidade se revela como instrumento fundamental de uma didática da distância social.

Palauras-chave: Empregadas Domésticas, Famílias de Camadas Médias, Reprodução Estratificada, Didática da Distância Social.

\footnotetext{
* Recebido para publicação em maio de 2007, aceito em agosto de 2007.

*** Antropóloga, professora da Universidade Federal de Juiz de Fora, Minas Gerais.juremagbrites@yahoo.com.br
} 
Empregadas domésticas e seus empregadores

Friendship and Inequality:

Gender, Generation and Class

Between Domestic Workers and their Employers

\begin{abstract}
In the execution of domestic tasks linked to the care and maintenance of middle-class families in Brazil - an activity performed, in most cases, by lower-income women who are not otherwise related to the employers - as well as in the forms of remuneration and relationships that develop between employers and maids, we witness the reproduction of a highly stratified system of gender, class, and color. The maintenance of the hierarchical system revealed by domestic service has been reinforced, in particular, by emotional ambiguities in the relationship between employers - especially women and children and the domestic workers. By analyzing examples drawn from our ethnographic study in Vitória (Espírito Santo), we will comment on how this ambiguity emerges as a fundamental instrument in the didactics of social distance
\end{abstract}

Key Words: Domestic Maids, Middle-class Families, Stratified Reproduction, Didactics of Social Distance. 
Jurema Brites

\section{Afeto e desigualdade}

Apesar das relações de poder evidentemente desiguais que, sem dúvida, caracterizam este relacionamento [entre empregada e patroa], é a ambigüidade afetiva da relação que exige mais análise. É na troca afetiva entre aquelas que podem pagar pela ajuda doméstica $e$ as [mulheres] pobres que oferecem seus serviços que as relações de classe são praticadas e reproduzidas (Goldstein, 2003).

Nos lares brasileiros de classe média $e$ alta, as relações familiares são cotidianamente permeadas pela presença de serviçais que realizam todo o trabalho doméstico, inclusive o cuidado das crianças. Como diz Donna Goldstein (2003), manter uma empregada doméstica é um sinal diacrítico na sociedade brasileira, que sinaliza a distância da pobreza.

Na própria realização das tarefas de cuidado e manutenção das casas e das pessoas - desempenhada, na esmagadora maioria das vezes, por mulheres pobres, fora da parentela dos empregadores -, assim como nas formas de remuneração e de relacionamento que se desenvolvem entre patrões e empregadas domésticas, reproduz-se um sistema altamente estratificado de gênero, classe e cor. ${ }^{1}$ No Brasil, a manutenção adequada desse sistema hierárquico que o serviço doméstico desvela tem sido reforçada, em particular, por uma ambigüidade afetiva ${ }^{2}$ entre os empregadores - sobretudo as mulheres $e$ as crianças - $e$ as trabalhadoras domésticas. Nas negociações de pagamentos extrasalariais, na troca de serviços não vinculados ao contrato, nas fofocas entre mulheres e trocas de carinhos com as crianças é impossível deixar de reconhecer a existência de uma carga forte

1 Elegendo um recorte que privilegia os fatores de gênero e classe, refiro ao leitor os trabalhos de Azerêdo (1989), Kofes (2001), Goldstein (2000) e Barcellos (1996) para uma discussão sobre a questão de cor nas relações entre empregadas domésticas e suas patroas no Brasil.

2 Conforme demonstra o trabalho de Goldstein (2000), citado na epígrafe deste artigo. 
Empregadas domésticas e seus empregadores

de afetividade. Esta, no entanto, não impede uma relação hierárquica, com clara demarcação entre chefe e subalterno, isto é, entre aqueles que podem comprar os serviços domésticos e aqueles que encontram, na oferta de seus serviços, uma das alternativas menos duras de sobrevivência no Brasil.

Trata-se, portanto, de um processo amplo de reprodução da desigualdade. Porém, a dimensão desse processo que nos interessa é centrada especificamente num tipo de atividade ligada à esfera doméstica - o "trabalho reprodutivo". Este trabalho é definido pela antropóloga Shellee Colen (1995:78) como o trabalho "físico, mental e emocional necessário para a geração, criação e socialização de crianças, assim como a manutenção de casas [households] e pessoas (da infância até a velhice)". ${ }^{3}$

Para descrever o modo como as tarefas "reprodutivas" têm sido distribuídas de acordo com hierarquias de classe, raça, grupos étnicos e gênero, Colen (1995) cunhou o conceito de reprodução estratificada. Através da análise de um contexto particular babás caribenhas (em geral, negras) em Nova York -, a autora mostra como o conjunto particular de valores familiares abraçados pelas mulheres profissionais da alta camada norte-americana só se sustenta com a ajuda de serviçais oriundas dos países pobres. ${ }^{4}$ Estas, por sua vez, deixam seus próprios filhos aos cuidados de outras mulheres no seu país de origem, de acordo com valores e modos de organização familiar diferentes, porém complementares àqueles de suas empregadoras. Uma certa desqualificação dos valores das mulheres caribenhas (que "abandonam" seus filhos aos cuidados de parentes e vizinhos), contrastada com a exaltação dos valores daquelas que contratam seus trabalhos, seria resultado

3 "The reproductive labor - physical, mental, and emotional - of bearing, raising, and socializing child and of creating and maintaining households and people (from infancy to old age)" (Colen, 1995:78).

${ }^{4}$ Com este caso, Colen (1995) introduz a dimensão transnacional nestas relações de desigualdade política, social e econômica. 
da desigualdade social, política e econômica que subjaz à relação. ${ }^{5}$ Assim, Colen (1995:78) demonstra que

a reprodução estratificada, em função particularmente da mercantilização (commodification) crescente do trabalho reprodutivo, reproduz ela mesma a estratificação ao refletir, reforçar $e$ intensificar as desigualdades nas quais se fundamenta.

Ao lado da noção de ambigüidade afetiva, cunhada por Goldstein (2000), o trabalho de Colen (1995) indica pistas importantes para nossa análise de relações no espaço doméstico brasileiro. Neste texto, ao descrever as relações que se desenvolvem na casa dos patrões, procuramos mostrar o jogo de interação entre empregadas e patroas provenientes de universos sociais distintos. Buscamos dar visibilidade à empregada doméstica no contexto da família brasileira, não como alvo do disciplinamento burguês (Martin-Fugier, 1979), tampouco como agente de poluição dentro do lar burguês higienizado (Perrot, 1988; Freire Costa, 1983). Antes, consideramos a doméstica dentro de certas famílias de classe média como uma mulher que, no convívio diário com outra mulher (a dona-de-casa), constrói, troca e remodela saberes domésticos, num ambiente onde cumplicidade $e$ antagonismo andam sempre de mãos dadas $e$ onde a desigualdade subentendida nessas trocas informa um exemplo típico de "reprodução estratificada".

É evidente que, à luz da teoria sobre relações de gênero, não poderíamos restringir o estudo apenas à relação entre as mulheres. ${ }^{6}$ Nossa proposta aqui é problematizar a trama de

5 A autora indica que, no contexto estadunidense, provavelmente em função da força do ideário da igualdade entre as pessoas na esfera pública, as mulheres pobres e, em geral, negras, não se submetem às condições do serviço doméstico remunerado, preferindo ficar em casa cuidando de seu próprio lar.

6 Analisando a trajetória do conceito de gênero no Brasil, Grossi e Miguel (1990) ressaltam a importância de realizar pesquisas que contemplem a perspectiva relacional da construção de gênero, enfocando as co-determinações dos sujeitos 
Empregadas domésticas e seus empregadores

relacionamentos domésticos, considerando critérios de gênero, idade e classe na distribuição das competências alocadas a cada personagem da cena doméstica. Aqui, enfocamos as famílias de classe média que compuseram nossa amostra ${ }^{7}$, onde é esperado da empregada doméstica o cumprimento das tarefas de limpeza, do cuidado da casa, das crianças, dos velhos e dos animais de forma discreta e afetiva. Com isso, os outros membros adultos podem se dedicar a atividades remuneradas fora do lar. A mãe, além de trabalhar fora, toma para si os cuidados com saúde, higiene e decoração do lar, além de amparar e gerenciar os afetos $e$ a rede de sociabilidade mais ampla. ${ }^{8}$ Do marido é esperada a parte principal da manutenção econômica da família, que dará respaldo ao investimento nas carreiras estudantis e sociais dos filhos. Poucas tarefas domésticas lhe são destinadas: às vezes, faz compras no supermercado, leva algum filho à escola ou repara algo na casa ou no carro. Não se destinam trabalhos domésticos para crianças e jovens, sobretudo, do sexo masculino. Em geral, esses jovens têm seus dias quase totalmente ocupados pela escola $e$, sobretudo, por cursos complementares de inglês, matemática, música, dança e esportes. ${ }^{9}$

envolvidos na construção destas identidades. Ver também Rosaldo (1995) e Scott (1995), entre outros.

7 Ao longo da pesquisa de campo (realizada no Espírito Santo, entre 1995 e 1998) fui percebendo o quanto não poderia eludir minha condição de "patroa". Abandonando ainda resquícios de uma ilusão objetivista, mergulhei no princípio da intersubjetividade, assumindo minha própria rede de sociabilidade como campo de informação. Optei por estudar tanto as relações que se travaram entre empregadas domésticas e seus empregadores, na casa da patroa, quanto por deslocar meu olhar para um universo cada vez mais distante das camadas médias intelectualizadas, investigando as relações familiares e de vizinhança, a partir da casa da empregada.

8 Neste aspecto, a organização da família de classe média no Brasil não parece muito diferente do "kin work", que cabe geralmente à dona-de-casa norteamericana descrita por Di Leonardi (1992).

9 Ver Salem (2007) para uma descrição ainda bastante atualizada da distribuição de tarefas segundo sexo e geração, dentro da família brasileira das camadas 
Veremos, portanto, no desenvolvimento do serviço doméstico, uma complementaridade de papéis em que, como no caso descrito por Colen (1995), por um lado, a empregada, pela sua contribuição nas tarefas domésticas, liberta os pais e filhos para promoverem um projeto familiar típico da classe média. $\mathrm{O}$ outro lado dessa colaboração, no entanto, aponta para o aspecto "estratificado" da relação - a distância social sutilmente marcada entre a empregada e os outros membros da unidade doméstica e, também, os antagonismos que surgem à medida que as empregadas procuram usar seu emprego para garantir a sobrevivência e promoção de suas próprias famílias.

\section{A relação com as crianças}

Edilene conta, com evidente orgulho, o que a filha de sua patroa, uma menina de cinco anos, disse para ela:

Lene, tu podia acertar na Sena, né? Aí tu só vinha aqui prá brincar comigo. Tu podias almoçar e deitar na cama da mamãe, para descansar, como ela faz. [Edilene fecha seu relato acrescentando] A idéia da menina! Deitar na sua cama?!

Essa pequena cena revela aspectos fundamentais da relação entre a empregada e a família para a qual trabalha. Aponta para o afeto que existe entre a empregada $e$ as crianças das quais ela cuida. Mas mostra também a consciência de ambas partes crianças e empregadas - da enorme distância social que as separa.

Começamos nossa discussão sobre a relação entre empregadas e filhos da patroa, aprofundando a questão do afeto. Em quase todas as casas de patrões que investiguei, as crianças, quando não estavam na escola, permaneciam grande parte de tempo com as empregadas, sem a presença dos pais. Os pais,

médias. Para uma perspectiva das experiências das família das classes médias brasileiras, ver Velho, 1989; Salem, 1986 e Heilborn, 1983. 
Empregadas domésticas e seus empregadores

trabalhando fora, deixavam essas crianças sob responsabilidade das domésticas $2 / 3$ do dia.

A intensidade de contato entre crianças e suas empregadas criava, em muitas situações, um vínculo que extrapolava a situação profissional. No pequeno álbum de fotografia de Edilene, encontramos, ao lado das fotos usuais de família (a mãe no caixão, seu próprio casamento, algumas $3 \times 4$ de irmãos $e$ sobrinhos) pelo menos uma foto de cada criança de quem cuidou em seus 28 anos de carreira doméstica. Quando ela está em casa, "depois do serviço", não pára de contar as façanhas de seus tutelados do momento - o que fulaninha falou, o que beltraninho fez..., de forma que seus vizinhos e familiares conhecem tudo dessas crianças (seus aniversários, sua roupa preferida...). É quase como se fossem parte da família da empregada. É comum mesmo quando o contrato de trabalho é suspenso - as empregadas continuarem a acompanhar a vida das crianças de quem tomaram conta. Telefona eventualmente para falar com elas, consulta uma colega que esteja trabalhando na rede de sociabilidade da ex-patroa, ou simplesmente calcula suas idades, de longe, lembrando da data de seus aniversários ou mantendo fotos das crianças nos seus álbuns de recordação.

Nesse contexto, uma mudança de emprego pode significar uma enorme perda afetiva. Edilene, por exemplo, caiu em depressão depois que seus ex-patrões se mudaram para uma cidade distante. A atual patroa chegou a ligar para a anterior (são amigas), sugerindo que a empregada fosse conhecer o lugar onde as crianças estavam instaladas e, talvez assim, sofresse menos com a separação. De fato, muitas vezes, o motivo para uma empregada agüentar um serviço mal pago é a dificuldade em se separar das crianças das quais toma conta.

Há sinais semelhantes do apego das crianças pelas "suas" empregadas. Uma patroa, por exemplo, relatou como o filho adoeceu quando o marido de Arlete, sua empregada, obrigou-a a deixar o emprego. Ouvi variantes desse tema em inúmeros outros 
relatos, sublinhando uma intensidade de contato que não deixa de ter conseqüências importantes.

Se, nos discursos sobre limpeza ${ }^{10}$, os patrões adultos são impermeáveis ao universo cultural das empregadas domésticas, o mesmo não acontece com as crianças. Elas dialogam com as empregadas, ouvem suas histórias, escutam a mesma música no radinho de pilha da cozinha, perguntam muitas coisas. Nessa intimidade cotidiana, as empregadas podem assumir conscientemente o papel de transmissoras de conhecimentos. Muitas meninas, filhas das patroas, eram estimuladas pelas empregadas a aprender o serviço doméstico. Elas aprendiam através de um exercício prático e de observação, enquanto as empregadas executavam seu serviço. Assisti a uma empregada dissecar uma galinha para ensinar à filha de quatro anos da patroa que esses animais não têm dentes, onde se formam os ovos e, para cozinhar, como se separam as partes. Como nas suas próprias casas, as empregadas transmitem para as crianças um conhecimento experimentado no cotidiano.

Mas existe outro tipo de saber transmitido de forma menos consciente, através da convivência e fofoca. Assim, não é raro, que a mãe saiba determinadas coisas sobre suas empregadas através dos comentários dos filhos pequenos. Eu mesma era constantemente informada pelas crianças. Certa vez, perguntei a uma empregada sobre um novo namorado e a menina da casa antecipou a resposta: "ela continua com aquele antigo. Eles passaram o fim-de-semana juntos". Contando sobre seus namoros, sobre suas brigas com vizinhos, as empregadas, muitas vezes, apresentam para as crianças de seus patrões um mundo menos dividido entre vida adulta e vida infantil. ${ }^{11}$ Algumas

${ }^{10} \mathrm{Em}$ Brites (2001) - de onde retiramos parte substancial deste artigo discutimos as concepções e práticas de higiene, organização e perspectivas estéticas diferencialmente construídas (e alvo de muitas disputas) por patroas $e$ empregadas domésticas.

${ }^{11}$ Lembremos aqui das possibilidades abertas pela análise de Ariès (1981) sobre a socialização de crianças na França do Antigo Regime. Era antes pela 
Empregadas domésticas e seus empregadores

meninas que conheci eram instruídas sobre a vida sexual pelas empregadas:

Inês [filha de patroa, 5 anos]: Ela me contou que transa com o Jorge, eles se encontram na Praça dos Namorados.

Jurema [pesquisadora]: E o que eles fazem?

Inês: Passa as mãos nos peitos, se beijam, dormem junto, ué!

Pauline (filha de outra patroa, 4 anos): Né que boceta é feio?

Inês: A Iris [empregada da casa da menina] me disse que o nome é bu -ce - ta.

Edilene [empregada da casa de Pauline]: É perereca que se diz.

Pauline: Perereca? Vagina não pula, pula?

Nessa convivência fluida entre adultos e crianças, percebi um trânsito de saberes, onde temas tabus entre as famílias de classe média eram atualizados na relação entre empregadas domésticas e as crianças dos patrões.

De forma significativa, quase não ouvi quase queixas, tão comuns em famílias européias e norte-americanas (Martin-Fugier, 1979), sobre o perigo de poluição moral das crianças através do contato com empregadas pouco instruídas. Nas entrevistas com os patrões foi possível observar que a educação dos filhos ocupa um lugar central nas suas preocupações. Inclusive, muitas vezes, justamente para pagar boas escolas particulares, pais e mães aceitam se afastar durante longas horas de suas famílias, tentando ganhar dinheiro suficiente para sustentar este padrão. Porém, esses pais da classe média que entrevistei quase nunca pensavam na empregada como uma fonte de aprendizado para os seus filhos. Raramente alguém empregava uma babá com

sociabilidade da rua e a convivência com adultos que as crianças adquiriam novos conhecimentos. 
responsabilidades especializadas, voltadas para os filhos (cuidar das crianças estava incluído entre outras tarefas, como cuidar da roupa, da casa e cozinhar).

As patroas ainda podem contar alguma história escabrosa sobre crianças torturadas por empregadas, mas não parecem associar essas histórias a suas próprias empregadas. Quando as patroas se referiam a pessoas concretas, nunca tinham um caso de maus tratos infantis por domésticas para contar. Pelo contrário, entre as pessoas pesquisadas, um grande alívio da maioria das mães-patroas era reconhecer a boa vontade das empregadas para com seus filhos. Apenas duas mães em toda a amostra expressaram temores quanto à influência da empregada; uma destas fez questão de contextualizar seus medos:

Nunca deixei meus filhos serem criados por empregada! Bem, agora eles são uns homens. Naquela época, com toda a moda da psicologia, eu não queria que meus filhos fossem assustados por Bicho Papão ou o Velho do Saco, sabe? Hoje me dou conta o quanto fui tola. Naquela época, as crianças eram criadas sob esses medos todos, mas que eram fantasia. Eram uma projeção irreal da violência. Hoje, ao contrário, ninguém mais conta história de bruxa, mas a violência pode estar dentro da tua casa através da empregada, ou do marido dela que venha te assaltar ou te seqüestrar.

Esta senhora era reconhecida, entre as amigas, como patroa demasiadamente rude com os serviçais, embora jamais fosse contestada diretamente durante os relatos. Ela parecia explicitar uma separação entre mundos morais, que a maioria das patroas tentava evitar.

Embora as patroas reclamassem o tempo inteiro de suas empregadas quanto à limpeza, excepcionalmente, relataram queixas sobre o tratamento com as crianças, seja de maus tratos seja quanto à educação. Apenas um pai expressou dúvidas sobre o que se passava entre sua filha e a empregada e, de forma 
Empregadas domésticas e seus empregadores

significativa, tratava-se de uma pessoa (filho de empregada doméstica) que tinha ascendido socialmente. Podemos supor que a ânsia de marcar a distinção entre ele e a subalterna o levou a demonstrar uma rigidez pouco comum em outras famílias de seu bairro. ${ }^{12}$ Por outro lado, seria por acaso que o único patrão de nossa pesquisa com vivência entre o mundo dos subalternos seja um dos raros a aventar possibilidades de relações sexualizadas entre crianças e empregadas?

Durante a pesquisa, me surpreendeu o silêncio acerca das relações sexuais que envolvessem empregadas e patrões, tão comentadas pela literatura das ciências sociais (Freyre, 1989), quanto pelo romance brasileiro (por exemplo, em Jorge Amado sobretudo, Gabriela - e Érico Veríssimo em o Tempo e Vento ou Solo de Clarineta, para mencionar apenas dois ícones). Ao longo dos três anos de investigação, além da desconfiança paterna, relatada acima, apenas dois casos referiam-se à sexualidade dessas relações. Certa vez, assisti uma patroa furiosa vociferar contra as empregadas do prédio onde morava, que a impediam de contratar uma nova empregada doméstica. As trabalhadoras me confidenciaram que uma menina foi espancada por esta mulher ao ser encontrada no banheiro com o esposo da patroa. Desde então, elas mantêm vigília para impedir que uma mulher desavisada possa ser contratada nesta casa. Em outro caso, ouvi queixas do próprio patrão. Um homem jovem e muito bonito dizia-se assediado pela empregada. Quando sua esposa viajava ao interior do Estado, a moça costumava desfilar pela casa apenas de calcinhas.

Não sei se a escassez de relatos e observações acerca da empregada como objeto sexual dos patrões é sinal de minha própria obscuridade. Mas presumo que, nas famílias de classe média intelectualizadas do universo urbano moderno, o imaginário sexual tenda, cada vez mais, a ser marcado por

${ }^{12}$ As diversas referências neste artigo sobre a "distinção" são inspiradas no trabalho de Elias (1990) e de Bourdieu (1994). 
fronteiras de classe. Ouvi mais meninos e homens adultos referindo-se às empregadas como "barangas" 13 , do que como alguém que pudesse ser objeto de desejos.

Tomando a intimidade das empregadas com as crianças pequenas, seria fácil pressupor uma relação cordial "quasefamiliar" como aquela descrita por Gilberto Freyre (1989) $)^{14}-e$, na literatura mais recente, por Roberto Da Matta (1987) - sobre a relação patrões-empregada. Mas não devemos esquecer que é nesse mesmo ambiente que as crianças dos patrões são socializadas numa lógica profundamente hierárquica, que coloca as empregadas em um mundo à parte.

A questão é: se existe tanta intimidade e afeto entre as crianças e suas empregadas, como se reproduzem patroas adultas com um sentido tão forte de hierarquia? Como se separam esses mundos? Não é regra entre os patrões investigados um tratamento ríspido com suas empregadas. As crianças aprendem a distância social entre elas e as empregadas domésticas através de outras vias - informações subliminares, por exemplo, nos dizeres dos seus pais e na disposição de espaço.

"Quarto de empregada", "banheiro de empregada", "dependência de empregada" são espaços de segregação, onde o respeito ensinado às crianças de classe média com as posses alheias desaparece. Os espaços destinados às empregadas na casa das patroas não respeitam a individualidade das trabalhadoras.

\footnotetext{
${ }^{13}$ Mulher muito feia, sem nenhum valor, repugnante.

${ }^{14}$ Como ilustra esta passagem de Casa Grande e Senzala: "Na ternura, na mímica excessiva, no catolicismo em que se deliciam nossos sentidos, na música, no andar, na fala no canto de ninar do menino pequeno, em tudo que é expressão sincera da vida, trazemos quase todos a marca da influência negra. Da escrava ou sinhama que nos embalou. Que nos deu de mamar. Que nos deu de comer, ela própria amolengando na mão o bolão de comida. Da negra velha que nos contou as primeiras histórias de bicho e de mal-assombrado. Da mulata que nos tirou o primeiro bicho-de-pé de uma coceira tão boa. Da que iniciou no amor físico e nos transmitiu, ao ranger da cama-de-vento, a primeira sensação completa de homem. Do moleque que foi o nosso primeiro companheiro de brinquedo" (Freyre, 1989:283).
} 
Empregadas domésticas e seus empregadores

Então, podem estar cheios de entulhos, vassouras, baldes e tudo que "não presta mais" ou que deve permanecer escondido para não perturbar a beleza e a ordem do lar. Como diz Goldstein (2003:80) ao analisar, a partir de seu estudo etnográfico no Rio de Janeiro, o "quartinho" e banheiro da empregada:

Essa peça, antes destinada a ser moradia, agora serve apenas para uso durante o dia. Trata-se de uma peça situada inevitavelmente atrás da cozinha e a lavanderia, onde, em geral, não cabe mais do que uma pequena cama de solteiro. O banheiro revela o verdadeiro status da empregada nesta casa. Essa área exígua mal tem lugar para um chuveiro e um vaso sanitário. Naqueles que vi, é comum encontrar a toilete sem assento, mas quando este existe, a arquitetura do espaço faz com que, quando se liga o chuveiro, a peça inteira inunda, inclusive o assento. É difícil, se não impossível, dar a esses espaços uma aparência limpa e organizada.

Entrevistando uma patroa em Praia Velha, aprendi o quanto as conversas e atitudes atrás dos bastidores, travadas entre os familiares, vão reproduzindo (às vezes não muito sutilmente) a naturalidade da posição subalterna para as pessoas que trabalham em suas casas. Aproveitando o duplo papel (de patroa $e$ pesquisadora) que a peculiaridade de minha inserção em campo proporcionou, desfrutei de momentos de muita intimidade com os informantes - momentos em que o roteiro encoberto ${ }^{15}$ entre as

\footnotetext{
${ }^{15}$ Em Domination and arts of resistence, Scott aprofunda suas idéias sobre "situações infra-políticas", sugerindo que todo e qualquer tipo de contato entre subalternos e superiores é guiado por elementos performáticos estereotipados e ritualizados. Refere-se à performance pública daquelas pessoas sujeitas a formas sistemáticas e elaboradas de subordinação social: o trabalhador ao chefe, o inquilino ou meeiro ao proprietário, o servo ao senhor, o escravo ao mestre, o intocável ao brâmane, um membro da raça sujeitada a um membro da raça dominante (Scott, 1990:2). Como contraponto a este comportamento prescrito, o autor oferece o conceito de roteiro encoberto (hidden transcript) para descrever
} 
patroas se revela (Scott, 1990). Durante a entrevista, estavam presentes a patroa, suas duas filhas (16 e 5 anos), meu assistente de pesquisa e eu. A patroa nos falava do quanto é necessário "tratar bem" as empregadas, sem deixar que as pessoas "confundam as coisas".

Outro dia, eu cheguei em casa e encontrei Alcina esparramada no sofá, assistindo TV. Os pés em cima da mesa, aqueles braços abertos sobre o encosto do sofá. Vê se pode? No mesmo lugar que depois eu e as minhas filhas vamos descansar! E ela lá, com aquela "inháca" no meu sofá!!

Então, ensinando como devemos nos comportar diante desta quebra de etiqueta, a patroa acrescenta:

Ah, não tive dúvida. Chamei ela num canto e conversei, com jeito, que é para não ofender, entende? Porque também não se pode ter um inimigo em casa, melhor é usar do bom entendimento, percebe?

- Olha aqui, Alcina, não fica bem você ficar aí sentada na sala de visitas. Não que eu me importe, mas pode chegar alguém. E se Ernesto [namorado da patroa] aparece para jantar? Não fica bem, entende? Se você quiser assistir TV, veja no quarto das meninas.

São nessas cenas de intimidade familiar que a relação com as domésticas serve de maneira paradigmática para socializar as crianças na lógica de uma sociedade hierárquica e estratificada. Exemplos que registrei no meu diário de campo demonstram como a segregação dos espaços é espelhada na atitude das crianças:

o comportamento que se desenrola atrás dos bastidores, longe da observação dos poderosos. 
Empregadas domésticas e seus empregadores

Pauline [4 anos]: Sabe, a Inês falou que a mãe dela disse que a gente não pode usar o banheiro da empregada.

Jurema: Por quê?

Pauline [5 anos]: Porque empregada tem doença na bunda.

Inês: É, a minha mãe explicou que se a gente senta no vaso onde a empregada senta, a gente pega doença, porque elas têm doença na bunda.

Dois amigos (7 e 10 anos) de Pauline (5 anos) chegaram na casa e encontraram a empregada deitada no sofá, assistindo à TV, enquanto Pauline desenhava numa mesa ao lado. Eles chamaram a menina e comentaram: "Manda ela sair daí. Onde já se viu empregada sentada no seu sofá! Mamãe não deixa a Neiva nem sentar na nossa cama!"

Devemos aqui lembrar da ambivalência demonstrada pela menina que imaginava como as coisas seriam diferentes se sua empregada pudesse ganhar na Sena. O mundo naturalizado da segregação de espaços, da poluição e da doença, é implicitamente associado a uma questão de classe. Se a empregada tivesse dinheiro, as coisas seriam diferentes. $\mathrm{O}$ afeto poderia ser traduzido em amizade e os espaços comungados. Mas, na situação atual, a distância social é tomada como um fato natural. Desde cedo, as crianças das casas patronais vão introduzindo no seu repertório os sinais da distância que deve-se manter dos serviçais, em pequenos rituais interpessoais de dominação, como tem nos ensinado Rollins (1990). ${ }^{16}$

É interessante pensar nessa separação de espaços como didática de uma distância social. Fátima Mernissi (1996), relatando sua experiência de menina em um harém marroquino, desfaz

16 "Os tipos de sistema econômico que institucionalizaram a desigualdade são variados, entretanto todos eles comportam rituais de comportamento interpessoais, que de certa maneira, reforçam para categorias inteiras da população o desejo de aceitar as formas, os usos e os significados destes rituais interpessoais que se exprimem nas relações entre domésticas negras e seus patrões brancos" (Rollins, 1990:63). 
nosso imaginário de prisão erótica de mulheres árabes, mostrando que lá dentro viviam famílias inteiras e que a segregação das mulheres, muito mais do que a proibição de saída à rua - porque esse grupo o fazia em determinadas ocasióes - constituía-se na introjeção do que significava hudud. O termo indica uma noção de fronteiras intransponíveis, mais do que um espaço concreto definido. O hudud dos homens não podia ser visitado, o cortinado de veludo que separa o andar da matriarca não podia ser transpassado.

O hudud serve aqui como metáfora para indicar o significado do modo como as empregadas ocupam os espaços na casa dos patrões e de como as crianças aprendem, através de suas rotinas cotidianas, a naturalizar a desigualdade, conciliando relações carregadas de enorme afeto com a, aparentemente, inevitável distância social.

\section{Referências bibliográficas}

ARIÈS, Philippe. História Social da Criança e da Família. $2^{\mathrm{a} e d . ~ R i o ~ d e ~}$ Janeiro, Zahar, 1981.

AZERÊDO, Sandra Maria da Mata. Relações entre empregadas e patroas: reflexões sobre o feminismo em países multirraciais. In: CosTA, A. e BRUSCHINI, C. (orgs.) Rebeldia e Submissão. Estudo sobre a condição feminina. São Paulo, Vértice, 1989, pp.195-220.

BARCEllos, Dayse. Família e Ascensão de Negros em Porto Alegre. Programa de Pós-Graduação em Antropologia - Doutorado - Museu Nacional/Universidade Federal do Rio de Janeiro, 1996.

BouRdiEu, Pierre. Stratégies de Reproduction et Modes de Domination. Actes de la Recherche en Science Sociales, $n^{\circ}$ 105, 1994, pp.3-12.

BRITES, Jurema. Afeto, Desigualdade e Rebeldia: bastidores do serviço doméstico. Tese de Doutorado, Programa de Pós-Graduação em Antropologia Social, UFRGS, Porto Alegre, 2001.

COLEN, Shellee. Like a mother to them: stratified reproduction and West Indian Childcare workers and employers in New York. In: GINSBURG, F. e RAPP, R. Conceiving the new world order: the global politics at reproduction. Berkley, University California Press, 1995, pp.78-102. 
Empregadas domésticas e seus empregadores

DA MATTA, Roberto. A Casa e a Rua. Rio de Janeiro, Editora Guanabara, 1987.

DI LEONARDI, Micaela. The female world of cards and holidays: women, families, and the work of kinship. In: THORNE, N. e YALOM, M. (coord.) Rethinking the family: some feminist questions. Boston, Northeastern University Press, 1992, pp.246-261.

EliAS, Norbert. O processo civilizador. Vol. 2. Rio de Janeiro, Zahar, 1990.

FREIRE COSTA, Jurandir. Ordem Médica e Norma Familiar. $3^{\mathrm{a} e d .}$ Rio de Janeiro, Graal, 1983.

Freyre, Gilberto. Casa Grande e Senzala. Rio de Janeiro, Ed. José Olimpio, 1989.

GolDSTEIN, Donna. The Aesthtics of Domination: Class, Culture, and the Lives of Domestic Workers. In: Laughter out of place: Race, Class and Sexuality in a Rio Shanytown. Berkeley, University of California Press, 2003.

GROSSI, Miriam e Miguel, Sônia M. A trajetória do conceito de gênero nos estudos sobre a mulher no Brasil - reflexões iniciais. Reunião Brasileira de Antropologia, mimeo., 1990.

HeILBORN, Maria Luiza. Visão de Mundo e Ethos de Camadas Médias Suburbanas. Comunicação apresentada na VII Reunião da ANPOCS, 1983.

KOFES, Maria Suely. Mulher, Mulheres - Identidade, diferença e desigualdade na relação entre patroas e empregadas. Campinas-SP, Ed. Unicamp, 2001.

Martin-Fugier, Anne. La Place des Bonnes. La domesticité feminine en 1900. Paris, Édition Grasset \& Fasquelle, 1979.

MERnISSI, Fatima. Sonhos de Transgressão: minha vida de menina num harém. São Paulo, Companhia das Letras, 1996.

Perrot, Michelle. Os Excluídos da História: Operários, Mulheres, Prisioneiros. Rio de Janeiro, Paz e Terra, 1988.

RolliNS, Judith. Entre Femmes: les domestique et leur patronnes. Actes de la Recherche, nº 84, 1990, pp.63-77. 
Jurema Brites

ROSALDO, Michelle. O uso e o abuso da Antropologia: reflexões sobre o feminismo e o entendimento intercultural. Horizontes Antropológicos, vol. 1, n 1,1995 , pp.11-36.

SALEM, Tânia. O casal grávido: disposições e dilemas de parceria igualitária. Rio de Janeiro, Editora FGV, 2007.

Família em Camadas Médias: uma perspectiva antropológica. $B I B, n^{\circ} 21$, Rio de Janeiro, ANPOCS, 1986.

O velho e o novo: um estudo de papéis e conflitos familiares. Petrópolis, Vozes, 1980.

SCOTT, James. Domination and the arts of resistence: hidden transcripts. New Haven, Yale University Press, 1990.

SCOTT, Joan. Gênero: uma categoria útil de análise histórica. Educação e Realidade, vol. 20, $\mathrm{n}^{\circ}$ 2, Porto Alegre, Faculdade de Educação/ UFRGS, jul./dez. 1995, pp.71-100.

VELHO, Gilberto. Subjetividade e sociedade: uma experiência de geração. Rio de Janeiro, Zahar, 1989. 